\title{
Thermodynamic Performance Evaluation of Single Stage Vapour Compression System Equipped with Liquid Vapour Heat Exchanger Using Eight Ecofriendly Refrigerants for Reducing Global Warming
}

\author{
Shobhit Mishra' ${ }^{1}$ M. Emran Khan ${ }^{2}$ \\ ${ }^{1}$ Scholar, Masters Degree, Thermal Engineering in Department of Mechanical Engineering, Jamia Millia Islamia, Delhi (India) \\ ${ }^{2}$ Professor Mechanical Engineering Department, Jamia Millia Islamia, Delhi, (India)
}

\begin{abstract}
This paper presents a detailed theoretical exergy analysis of single stage vapour compression refrigeration system using refrigerants R-410A, R-407C, R-600A, R-290, R-32, R-134A, HFO-1234yf, HFO-1234ze. For exergy analysis a mathematical computational model is developed in engineering equation solver (EES) for calculating coefficient of performance (COP), exergetic efficiency, exergy destruction ratio (EDR) and the effect of evaporator temp, effectiveness of liquid vapour heat exchanger on COP, EDR, and exergetic efficiency is presented. Among the refrigerants taken HFO-1234yf and HFO-1234ze shows the promising results because of ultra low global warming potential (GWP) and zero ozone depletion potential (ODP).
\end{abstract}

Keywords: Exergy, EDR, COP, Exergetic Efficiency, HFO-1234yf, HFO-1234ze, Vapour compression system with LVHE, GWP

\section{Introduction}

Refrigeration is a science which is used to produce low temperature or ultra low temperature (depending on the application) as compared to the surrounding by absorbing heat at a low temperature and rejecting it at a higher temperature working on a cycle. Refrigeration and air conditioning performs different functions, former one controls only one thing i.e. temperature while the latter one controls velocity of air, purity of air, humidity along with temperature. In 1974, large scale use of CFC, HCFC in mobile air conditioning and stationary refrigeration application depleted the ozone layer in stratosphere thus created a hole over the antartic region. This incident triggered an alarming issue on reducing or phasing out of CFC and HCFC substances that depletes the ozone layer due to environmental effect, hence Montreal protocol came into effect in 1987 [5].

The next problem arises due to GWP, so Kyoto protocol (1997) proposed the use of refrigerants having ultra low GWP and zero ODP [6]. Globally a program being pursued for phasing out the refrigerants having high chlorine content, high global warming potential and ozone depletion potential for the sake of environmental problems. Alternative to CFC and HCFCs are other substances such as azeotropic mixtures refrigerants with their zero ODP have been extensively used in many refrigeration applications (domestic or industrial). A new series called „hydrofluoroolefins"e is currently in the development range because of favourable environment properties, ultra low GWP and zero ODP. HFO-1234ze (trans-1, 3, 3, 3-tetrafluoroprop-1-ene) and HFO-1234yf (2, 3, 3, 3 -Tetrafluoropropene) have ultra low Global Warming Potential (GWP) of 6 and 4 respectively and zero Ozone Depletion Potential (ODP). In-fact General motors (USA) started using HFO-1234yf in all of its brands from 2013.

It has been clear from table 1, R-600a and R-290a also known as methylpropane or isobutane and isopropane respectively, have zero ODP and very low GWP (having a value of 3.3 times the GWP of carbon dioxide) and can serve as a functional replacement of R-12, R-22, R-134a, and other CFC and HFC refrigerants in conventional stationary refrigeration and air conditioning system, however flammability issue is still associated with these refrigerants. R-32 (difluoromethane) has a 100year GWP of 675 times that of $\mathrm{CO}_{2}$, though slightly flammable.

From 2011, European parliament has published a directive that will phase out refrigerants with a global warming potential (GWP) exceeding 150 in automotive air conditioning (GWP = 100 year warming potential of one kilogram of a gas relative to one kilogram of $\mathrm{CO}_{2}$ ). Out of the eight selected refrigerants taken only four refrigerants namely HFO-1234yf, HFO-1234ze, R-600a and R-290 satisfy the above condition. But flammability issue is associated with R-600a and R-290, hence hydrofluoroolefins served as the next generation refrigerants in the MAC (mobile air conditioning) and stationary refrigeration application [13].

Jyoti soni et al. (2013) performed theoretical exergy analysis of vapour compression refrigeration cycle using R-404A, R-407C and R-410A. Firstly she found that COP and exergetic efficiency of R-407C are better than that of $\mathrm{R}-404 \mathrm{~A}$ and R-410A. Also EDR of R-410A is higher than that of R-407C and R-404A. Secondly with increase in effectiveness of liquid vapour heat exchanger COP and exergetic efficiency decreases while EDR increases. The total COP of R-407C, R-410A, R404A decreases by $17.39 \%, 22.82 \%, 20.91 \%$ respectively and exergetic 


\section{International Journal of Science and Research (IJSR) \\ ISSN (Online): 2319-7064}

Index Copernicus Value (2013): 6.14 | Impact Factor (2015): 6.391

efficiency decreases by 9.05\%, 5.85\%, 6.05\% for R407C, R-410A, R-404A respectively [10].

Aprea and Greco et al. (2002) compared the performance between R22 and R407C (a zeotropic blend) and suggested that R407C is a promising drop-in substitute for R22. Experimental tests were performed in a vapour compression plant with a reciprocating compressor to evaluate the compressor performance using R407C in comparison to R22. The plant overall exergetic performance was also evaluated and revealed that R22 performance is consistently better than that of its candidate substitute (R407C) [9].

Shiva Reddy et al. (2012) has investigated the exergetic analysis of vapour compression refrigeration system with R134a, R143a, R152a, R404A, R407C, R410A, R502, and $\mathrm{R} 507 \mathrm{~A}$. In this he studied that R134a performed better in all respect and R407 performed poor [11]

Venkataramana et al. (2010) has performed exergy analysis of an air conditioner containing refrigerant R22, substituted by R134a, R290, and R407. Results indicate that COP and exergy efficiency of R290 vapor compression refrigeration system (VCRS) is higher and the values for R407 and R134a VCRS were found to be lower in comparison of R22 [8].

Bilal and Syed et al. (2011) investigated performance degradation due to fouling in a vapour compression cycle for various applications. For the analysis he considers the two sets of refrigerants depending upon the assumption and their some properties. Considering the first set of refrigerants R134a, R410A and R407C while second set include the refrigerants of R717, R404A and R290. From a first law standpoint, the COP of R134a always performs better than R410A and R407C unless only the evaporator is being fouled. From a second law standpoint, the second law efficiency of R134a performs the best in all cases. From a first law standpoint, the COP of R717 always performs better than R404A and R290 unless only the evaporator is being fouled. From a second law standpoint, the second law efficiency of R717 performs the best in all cases. Volumetric efficiency of R410A and R717 remained highest under all the respective conditions. Furthermore, performance degradation of evaporator has larger effect on compressor power consumption while the performance degradation of condenser has larger effect on COP of the vapour compression cycle [12].

Leck et al. (2010) have reported the results of an atmospheric modeling study in which he found that replacing HFC-134a in vehicle air conditioning units with HFO-1234yf would have little, or no impact on tropospheric ozone levels (impact was less than $0.01 \%$ of total ozone formed during the simulations) [3].

Brown et al. (2009) gives an overview of the feasibility of HFOs as replacement refrigerants. The researches on HFO are mostly focused on measuring or reckoning their thermodynamic properties. Thermodynamic and transport properties of HFO-1234yf and HFO-1234ze fluids are available in REFPROP [4].

\section{Cycle Description and Model}

Vapour compression cycle is highly irreversible cycle due to throttling process involved and operate on high grade energy i.e. work. Vapour Compression system consist of the following process:

1)Process, 1-2: superheating of saturated vapour refrigerant in LVHE at constant pressure

2)Process, 2-3: actual compression of superheated vapour refrigerant in the compressor.

3)Process,3-4: constant pressure heat rejection in the condenser

4)Process 4-5: subcooling of saturated liquid refrigerant in LVHE at constant pressure

5)Process5-6: throttling process (isenthalpic expansion)

6)Process 6-1: constant pressure heat absorbtion in the evaporator

Figure 1- 3, shows the schematic representation of vapour compression cycle equipped with LVHE on T-s and P-h diagram.

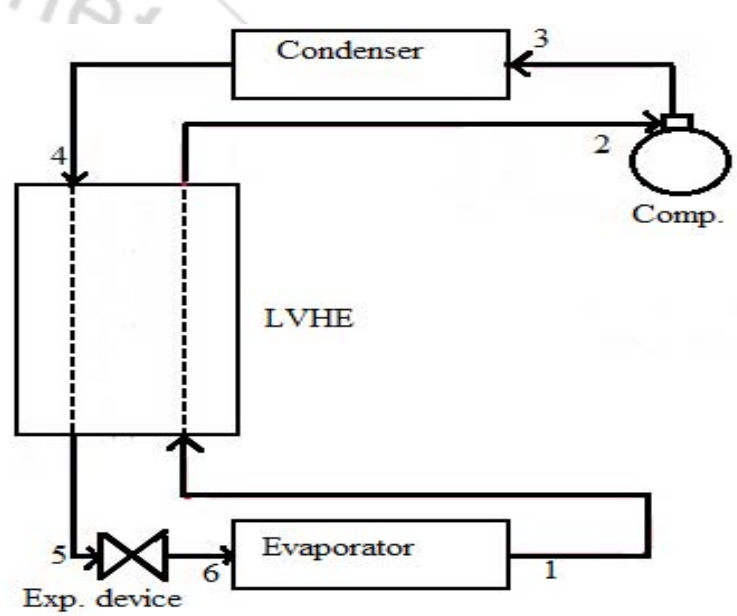

Figure 1: Vapour compression cycle with LVHE.

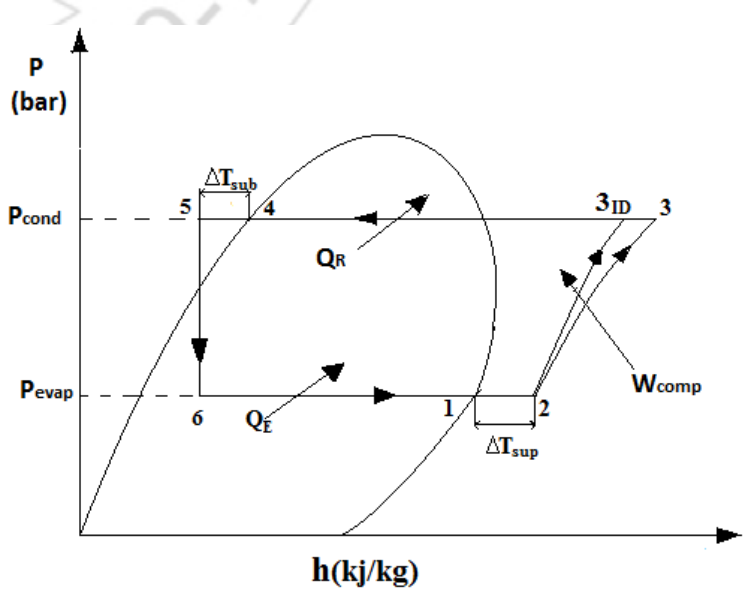

Figure 2: Pressure - Enthalpy diagram of vapour compression cycle with LVHE 


\section{International Journal of Science and Research (IJSR) \\ ISSN (Online): 2319-7064}

Index Copernicus Value (2013): 6.14 | Impact Factor (2015): 6.391

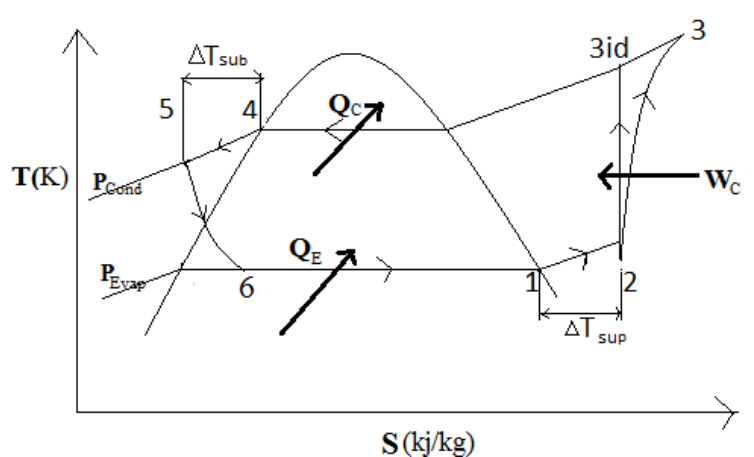

Figure 3: Temp-Entropy diagram of vapour compression cycle with LVHE.

\section{Exergy Analysis}

A mathematical computational model is developed for performing exergy analysis of the system using EES software [2].
For Exergy analyses following assumptions are made:

- Degree of subcooling of liquid refrigerant in lvhe, $\Delta T_{\text {sub }}$ $=5 \mathrm{~K}$.

- Isentropic efficiency of compressor $\eta_{\text {comp }}=.9$

- Difference between evaporator and space temperature $T_{r}-T_{e}=16 \mathrm{~K}$

- Effectiveness of liquid vapour heat exchanger, $\varepsilon=0.7$.

- Evaporator temperature, $T_{\text {evap }}=-40^{\circ} \mathrm{C}$ to $5^{\circ} \mathrm{C}$.

- Condenser temperature, $T_{\text {cond }}=45^{\circ} \mathrm{C}$.

- Mass flow rate of refrigerant, . $\mathrm{r}=1 \mathrm{~kg} / \mathrm{s}$

- Surrounding temperature, $T_{0}=300 \mathrm{~K}$.

- Pressure losses in pipelines are neglected.

- Steady state operations are considered in all components.

Table 1: Thermophysical Properties [14]

\begin{tabular}{|c|c|c|c|c|c|c|c|c|}
\hline Refrigerants & Formulae & ODP & $G W P$ & $\begin{array}{c}\text { Molar } \\
\text { Mass }(g \\
m o l^{-1}\end{array}$ & $\begin{array}{c}\text { NBP } \\
(\mathrm{K})\end{array}$ & $\begin{array}{c}\text { Critical } \\
\text { Pressure } \\
{[\mathrm{MPa}]}\end{array}$ & $\begin{array}{c}\text { Critical } \\
\text { temp }[\mathrm{K}]\end{array}$ & Remarks \\
\hline HFO-1234yf & $\mathrm{CF}_{3} \mathrm{CF}=\mathrm{CH}_{2}$ & 0 & 4 & 114.0416 & 243.7 & 3.382 & 367.85 & $\begin{array}{c}\text { Low GWP, but a little } \\
\text { flammable (with double bond) }\end{array}$ \\
\hline HFO-1234ze & $\mathrm{CHF}=\mathrm{CHCF}_{3}$ & 0 & 6 & 114.0416 & 254.2 & 3.682 & 382.51 & $\begin{array}{c}\text { Low GWP, but a little } \\
\text { flammable (with double bond) }\end{array}$ \\
\hline $\mathrm{R}-134 \mathrm{a}$ & $\mathrm{CH}_{2} \mathrm{FCF}_{3}$ & 0 & 1430 & 102 & 246.93 & 4.06 & 374.06 & $\begin{array}{c}\text { CFC-22 alternative for mobile } \\
\text { air conditioner }\end{array}$ \\
\hline $\mathrm{R}-600 \mathrm{a}$ & $\mathrm{C}_{4} \mathrm{H}_{10}$ & 0 & 3 & 58.12 & 261.4 & 3.66 & 408 & $\begin{array}{c}\text { CFC alternative for domestic } \\
\text { refrigerator, flammable }\end{array}$ \\
\hline $\mathrm{R}-290$ & $\mathrm{CH}_{3} \mathrm{CH}_{2} \mathrm{CH}_{3}$ & 0 & 3 & 44.1 & 230.9 & 4.25 & 369.8 & $\begin{array}{c}\text { Natural refrigerant, but } \\
\text { flammable }\end{array}$ \\
\hline $\mathrm{R}-32$ & $\mathrm{CH}_{2} \mathrm{~F}_{2}($ & 0 & 675 & 52.0234 & 221.5 & 5.785 & 351.26 & $\begin{array}{c}\text { Low GWP and high } \\
\text { performance, but flammable }\end{array}$ \\
\hline $\mathrm{R}-410 \mathrm{a}$ & $\mathrm{C}_{3} \mathrm{~F}_{4} \mathrm{H}_{2}$ & 0 & 1730 & 114.04 & 221.64 & 4.9 & 344.43 & $\begin{array}{c}\text { near-azeotropic blend of R-32 } \\
\text { 32 and R-125 }\end{array}$ \\
\hline $\mathrm{R}-407 \mathrm{c}$ & $\mathrm{CH}_{3} \mathrm{CHF}_{2}$ & 0 & 1530 & 66.05 & 229.37 & 4.6191 & 345.5 & $\begin{array}{c}\text { zeotropic hydrofluorocarbon } \\
\text { blend of R-32, R-125, and R- } \\
134 a\end{array}$ \\
\hline
\end{tabular}

From first law of thermodynamics, COP represents running cost of the system higher the COP, lower is the running cost of the system. COP is defined as the ratio of refrigerating effect to the work input required. COP is the measure of effectiveness and performance of the cycle and is given as,

$$
\mathrm{COP}=\frac{\dot{\mathrm{Q} e}}{\dot{\mathrm{W} c o m p}}=\frac{\mathrm{h} 1-\mathrm{h} 6}{\mathrm{~h} 3-\mathrm{h} 2}
$$

$\dot{\mathrm{Q}}_{\mathrm{e}}=$ Rate of heat transfer in evaporator $(\mathrm{kW})$

$\dot{\mathrm{W}}_{\text {comp }}=$ Rate of work input to compressor (KW)

From second law of thermodynamic exergy analysis is useful for improving the efficiency of energy resources use, since it quantifies the locations, types and magnitude of losses. Exergy analysis is a powerful tool in the design, optimization, and performance evaluation of energy system. It is defined as the maximum work obtainable in a process as the system comes in equilibrium with the surrounding.
First law is the law of conservation of energy or quantitative law while second law is the law of degradation of energy or qualitative law [1].

3.1 Exergy balance for a control volume undergoing steady state process is expressed as

$$
\dot{\mathrm{E}}_{\mathrm{i}}+\dot{\mathrm{E}}_{\mathrm{K}}^{\mathrm{Q}}=\dot{\mathrm{E}}_{\mathrm{e}}+\dot{\mathrm{W}}+\mathrm{ED}
$$

where,

$\dot{\mathrm{E}}_{\mathrm{i}}=\sum_{\mathrm{IN}} \dot{\mathrm{m}} \mathrm{e}$, Physical exergy of the system entering the control region (KW)

$\dot{\mathrm{E}}_{\mathrm{e}}=\sum_{\text {out }} \dot{\mathrm{m}} \mathrm{e}$, Physical exergy of the system leaving the control region (KW)

Above equation are valid by neglecting kinetic exergy and potential exergy and chemical exergy of the component. 


\section{International Journal of Science and Research (IJSR) \\ ISSN (Online): 2319-7064 \\ Index Copernicus Value (2013): 6.14 | Impact Factor (2015): 6.391}

$\dot{\mathrm{E}}_{\mathrm{K}}^{\mathrm{Q}}=\sum\left[\dot{\mathrm{Q}}_{\mathrm{K}} \frac{\mathrm{T}-\mathrm{To}}{\mathrm{T}}\right]$, represents thermal exergy flow rate, which gives exergy transfer rate corresponding to the heat transfer rate $\dot{Q}$ when the temperature at the control surface where heat transfer is occurring is $T$ and the exergy associated with work transfer to and from the control region (KW), if the Kth component is condenser then thermal exergy flow rate is zero because the temp difference between the system boundary and the immediate surrounding is zero.

$$
\mathrm{e}=\left(\mathrm{h}-\mathrm{T}_{0} \mathrm{~s}\right)-\left(\mathrm{h}_{0}-\mathrm{T}_{0} \mathrm{~s}_{0}\right)
$$

$\mathrm{e}=$ Specific Exergy $(\mathrm{kj} / \mathrm{kg})$

$\mathrm{h}=$ specific enthalpy $(\mathrm{kj} / \mathrm{kg})$

$\mathrm{s}=$ specific entropy $(\mathrm{kj} / \mathrm{kg})$

$\mathrm{ED}=$ Rate of exergy destruction in the component $(\mathrm{kW})$

$\dot{\mathrm{W}}=$ Work rate of the system $(\mathrm{kW})$

. $\mathrm{r}=$ mass flow rate of refrigerant $(\mathrm{kg} / \mathrm{s})$

$\mathrm{T}_{\mathrm{r}}=$ Temperature of space to be cooled $(\mathrm{K})$

\subsection{Exergy Destruction (ED) in the system components}

\section{- Evaporator,}

$$
\begin{aligned}
\mathrm{ED}_{\text {Evap }} & =\dot{\mathrm{E}}_{6}+\dot{\mathrm{Q}}_{\mathrm{e}}\left(1-\frac{\mathrm{To}}{\mathrm{Tr}}\right)-\dot{\mathrm{E}}_{1} \\
& =\cdot \mathrm{r}\left[\left(\mathrm{h}_{6}-\mathrm{h}_{1}\right)-\mathrm{T}_{\mathrm{o}}\left(\mathrm{S}_{6}-\mathrm{s}_{1}\right)\right]+\dot{\mathrm{Q}}_{\mathrm{e}}\left(1-\frac{\mathrm{To}}{\mathrm{Tr}}\right)
\end{aligned}
$$

- Compressor,

$$
\left.\mathrm{ED}_{\text {comp }}=\dot{\mathrm{E}}_{2}+\dot{\mathrm{W}}_{\text {comp }}-\dot{\mathrm{E}}_{3}=\text { r } r_{\mathrm{r}} \mathrm{T}_{\mathrm{o}}\left(\mathrm{S}_{3}-\mathrm{S}_{2}\right)\right]
$$

- Condenser,

$$
\mathrm{ED}_{\mathrm{c}}=\dot{\mathrm{E}}_{3}-\dot{\mathrm{E}}_{4}=\text {.r }\left[\left(\mathrm{h}_{3}-\mathrm{h}_{4}\right)-\mathrm{T}_{\mathrm{o}}\left(\mathrm{s}_{3}-\mathrm{s}_{4}\right)\right]
$$

- Liquid vapour heat exchanger, $\mathrm{ED}_{\text {lvhe }}=\left(\dot{\mathrm{E}}_{4}-\dot{\mathrm{E}}_{5)}+\left(\dot{\mathrm{E}}_{1}-\dot{\mathrm{E}}_{2}\right)\right.$

$$
=\dot{\mathrm{m}}_{\mathrm{r}}\left[\left(\mathrm{h}_{4}-\mathrm{h}_{5}\right)+\left(\mathrm{h}_{1}-\mathrm{h}_{2}\right)-\mathrm{T}_{\mathrm{o}}\left[\left(\mathrm{s}_{4}-\mathrm{s}_{5}\right)+\left(\mathrm{s}_{1}-\mathrm{s}_{2}\right)\right]\right.
$$

- Throttle Valve,

$$
\mathrm{ED}_{\mathrm{tv}}=\dot{\mathrm{E}}_{5}-\dot{\mathrm{E}}_{6}=\dot{\mathrm{m}}_{\mathrm{r}}\left[\mathrm{T}_{\mathrm{o}}\left(\mathrm{S}_{5}-\mathrm{s}_{6}\right)\right]
$$

\subsection{Exergetic Efficiency ( $\eta_{\mathrm{EE}}$}

Exergetic efficiency is defined as the ratio of minimum exergy required to do a given task to the actual exergy consumed.

$\eta_{E E}=\frac{\text { minimum exergy required to do a given task }}{}$

Exergetic efficiency is also given by,

$$
\eta_{\mathrm{EE}}=\frac{\dot{\mathrm{Q}} \mathrm{e}\left(1-\frac{\mathrm{To}}{\mathrm{Tr}}\right)}{\dot{\mathrm{W}} \mathrm{comp}}=\frac{\mathrm{COP} \mathrm{vcr}}{\text { COP rev }}
$$

where,

$\mathrm{COP}_{\text {rev }}=$ Coefficient of performance of reversible refrigerator operating between temperature $T_{0}$ and $T_{r}$ $\mathrm{COP}_{\mathrm{VCR}}=$ Coefficient of performance of actual vapour compression cycle.

\subsection{Total Exergy destruction}

Total exergy destruction in the system is the sum of the exergy destruction in different components of the system and is given by:

$$
\mathrm{ED}_{\text {total }}=\mathrm{ED}_{\mathrm{E}}+\mathrm{ED}_{\mathrm{comp}}+\mathrm{ED}_{\mathrm{c}}+\mathrm{ED}_{\text {lvhe }}+\mathrm{ED}_{\mathrm{tv}}
$$

\subsection{Exergy destruction ratio (EDR)}

EDR is defined as the ratio of total exergy destruction in the system to minimum exergy required in doing a given task and is given by,

$$
\begin{aligned}
& \mathrm{EDR}=\frac{\text { ED total }}{\dot{\mathrm{E}}_{\mathrm{E}}^{\mathrm{Q}}} \text {, also } \\
& \qquad=\frac{\text { COP rev }}{\text { COP vcr }}-1=\frac{1}{\eta \text { exergetic }}-1
\end{aligned}
$$

\section{Results and Discussion}

Figure 4, depicts clearly the variation of COP with evaporator temperature and following things can be concluded, as we increase the temperature , pressure ratio decreases, which directly reduces the compressor work and finally increases the refrigerating capacity hence leading to an increase in COP of system. It is seen from the calculation that the highest COP is seen in case of R600a, followed by HFO-1234ze, R-134a, R-290, HFO1234yf, R-32, R-410a, R-407c. The COP of R-600a, HFO1234ze, R-134a，R-290, HFO-1234yf，R-32，R-410a is $16.33 \%$, 13.87\%, 13.25\%, 10.47\%, 7.58\%, 5.71\%, 1.39\% is higher than R-407c respectively at evaporator temp of $278 \mathrm{k}$.

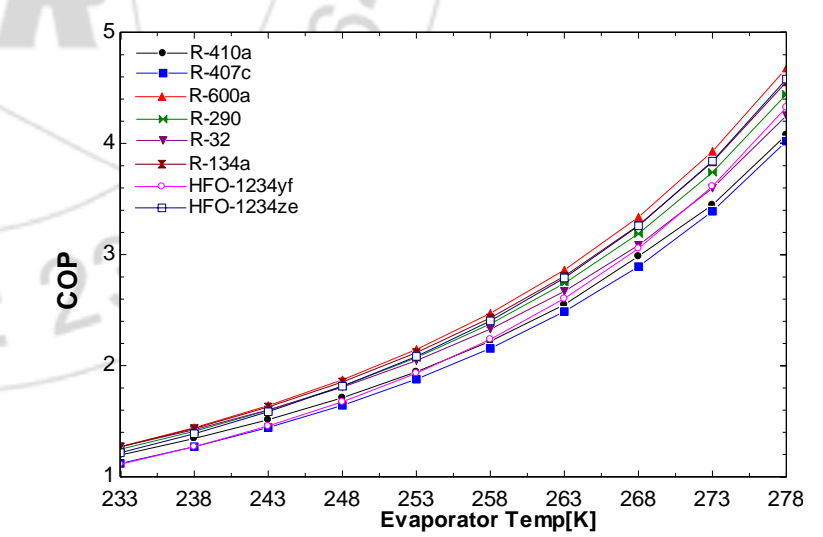

Figure 4: shows the variation of COP vs evaporator temp $[\mathrm{k}]$ 


\section{International Journal of Science and Research (IJSR) \\ ISSN (Online): 2319-7064}

Index Copernicus Value (2013): 6.14 | Impact Factor (2015): 6.391

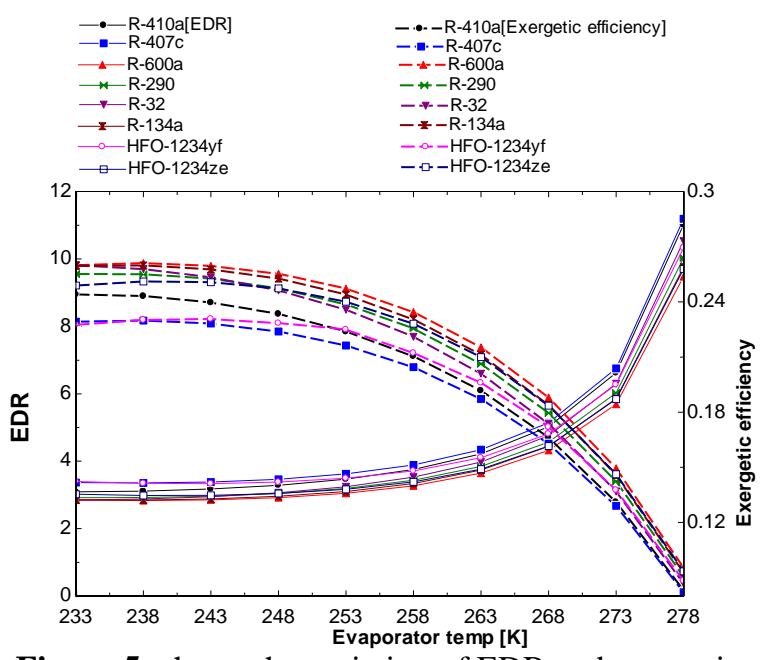

Figure 5: shows the variation of EDR and exergetic efficiency vs evaporator temp [k]

Figure 5 shows the variation of $\eta_{\text {exergetic }}$ with evaporator temperature. $\eta_{\text {exergetic }}$ first rises and then falls, there are two possible factors for this phenomena to occur. First parameter is thermal exergy flow in the evaporator i.e. $\dot{Q}_{e} \mid$ $\left(1-\frac{\mathrm{To}}{\mathrm{Tr}}\right) \mid$, Refrigerating effect increases due to increase in evaporator temperature, but the term $\left|\left(1-\frac{\mathrm{To}}{\mathrm{Tr}}\right)\right|$ decreases since $T_{r}$ approaches to $T_{o}$ and second factor is compressor work which reduces with the increment in the evaporator temperature i.e. the combined effect of $\dot{Q}_{e}$ and $\dot{\mathrm{W}}_{\text {comp }}$ is to increase the $\eta_{\text {exergetic }}$ till it reaches the maximum value and the evaporator temp at this efficiency is optimum evaporator temperature, beyond which the combined effect is to decrease the $\eta_{\text {exergetic. }} \eta_{\text {exergetic }}$ of R-600a, R-32, R$134 \mathrm{a}$, is almost equal and is $14.28 \%$, higher then HFO$1234 y f$ at lower end of evaporator temp i.e. 233K. Also $\eta_{\text {exergetic }}$ of R-290, HFO-1234ze, R-410a is12.13\%, 9.40\%, $7.2 \%$ higher then HFO-1234yf at lower end of evaporator temperature. $\eta_{\text {exergetic }}$ of R-407c and HFO-1234yf is almost equal. Figure 5, also represents the variation of EDR with evaporator temperature and it is opposite to $\eta_{\text {exergetic. }}$ From the calculation it has been observed that EDR of HFO$1234 y f$ is highest, since EDR is reverse of $\eta_{\text {exergetic, }}$, hence reverse is true.

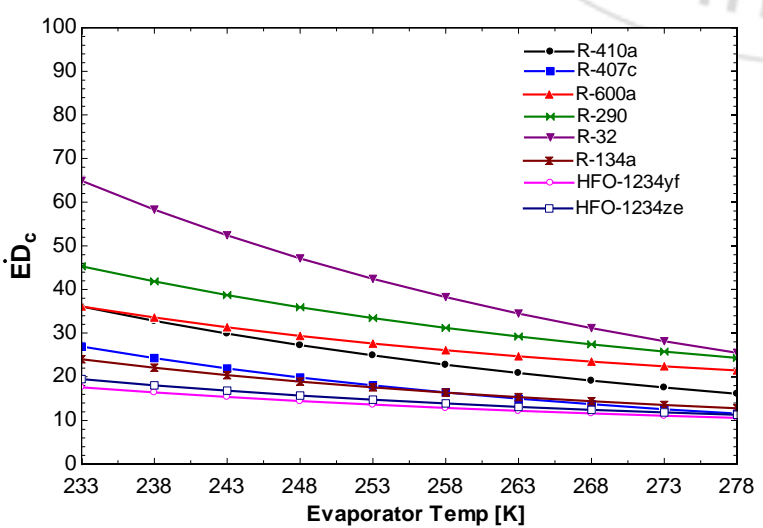

Figure 6: shows the variation of exergy destruction in condenser vs evaporator temp [k].

Figure 6, depicts that Exergy destruction or irreversibility in condenser is highest in case of R-32, and then it decreases in the following manner for other refrigerants,
R-290, R-600a, R-410a, R-407c, R-134a, HFO-1234ze, HFO-1234yf. Irreversibility is decreases as the evaporator temperature increase. Refrigerant HFO-1234yf shows the least irreversibility.

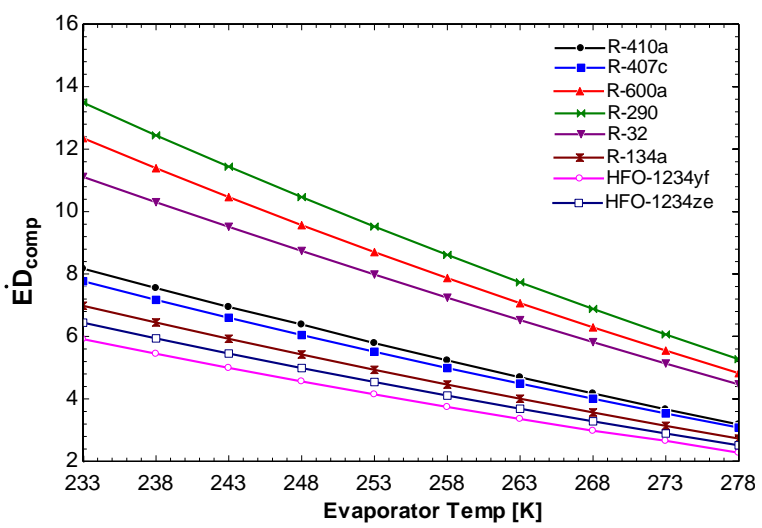

Figure 7: shows the variation of exergy destruction in compressor vs evaporator temp [k]

Figure 7, depicts that Irreversibility in compressor is highest in case of R-290, R-600a, R-32, R-410a, R-407c, R-134a, HFO-1234ze, HFO-1234yf. Irreversibility is decreases as the evaporator temperature increase. Refrigerant HFO-1234yf shows the least irreversibility.

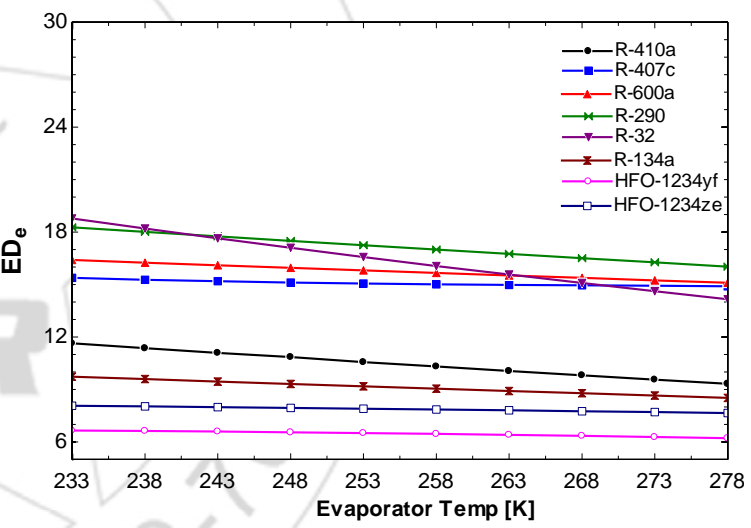

Figure 8: shows the variation of exergy destruction in evaporator vs evaporator temp [k]

Figure 8, depicts that Irreversibility or lost work in evaporator is maximum in R-32, R-290, R-600a, R-407c, R-410a, R-134a, HFO-1234ze, HFO-1234yf. Irreversibility is decreases as the evaporator temperature increase. Refrigerant HFO-1234yf shows the least irreversibility.

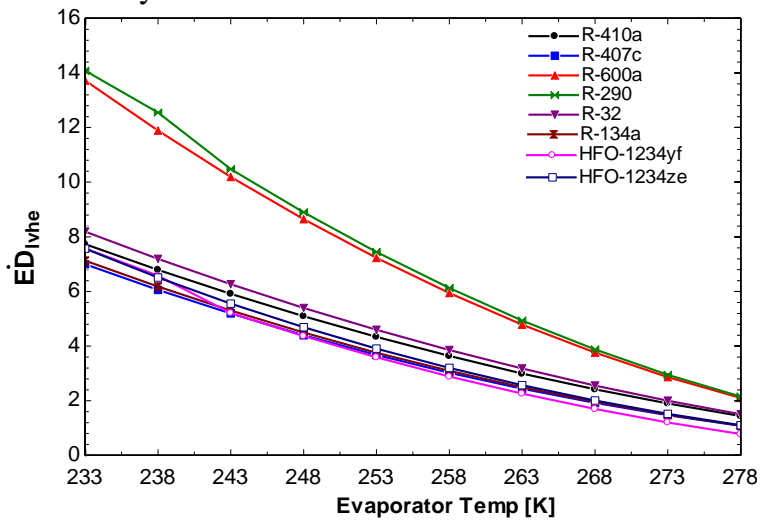

Figure 9: shows the variation of exergy destruction in LVHE vs evaporator temp [k] 


\section{International Journal of Science and Research (IJSR) \\ ISSN (Online): 2319-7064 \\ Index Copernicus Value (2013): 6.14 | Impact Factor (2015): 6.391}

Figure 9, depicts that Irreversibility or lost work in LVHE is highest for R-290, and decreases in the following manner, R-600a, R-32, R-410a, HFO-1234ze, R-134a. Also exergy destruction is least for refrigerant R-407c at lower end of evaporator temperature and it is least for HFO-1234yf at higher end of evaporator temperature.

Figure 10, depicts that Irreversibility or lost work in throttling valve is highest for R-290, and decreases in the following manner, R-290, R-600a, R-32, R-410a, R-134a, HFO-1234ze. Also exergy destruction is least for refrigerant HFO-1234yf at lower end of evaporator temperature and it is least for R-407c at higher end of evaporator temperature.

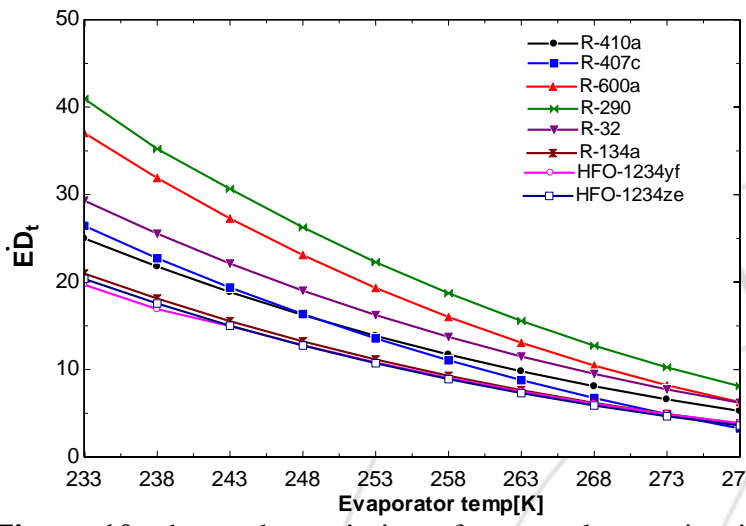

Figure 10: shows the variation of exergy destruction in compressor vs evaporator temp [k]

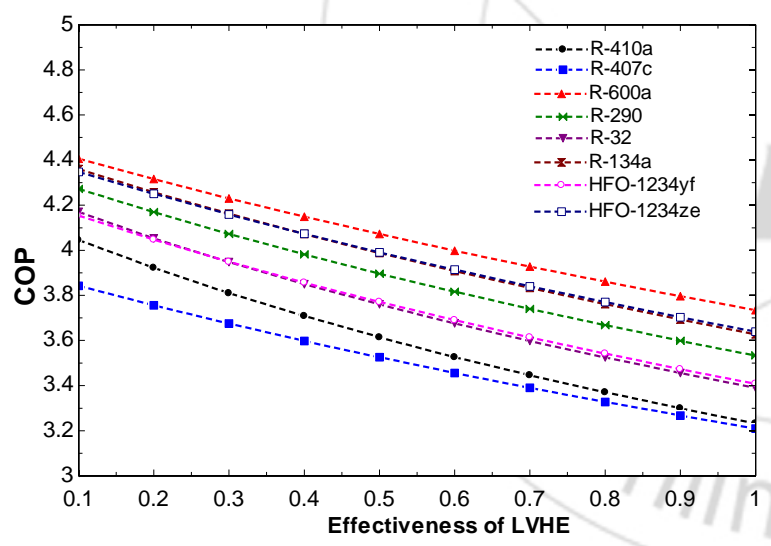

Figure 11: shows the variation of COP vs Effectiveness of liquid vapour heat exchanger $(\varepsilon$, lvhe) $(\mathrm{Te}=273 \mathrm{~K}$, $\mathrm{Tc}=318 \mathrm{~K})$

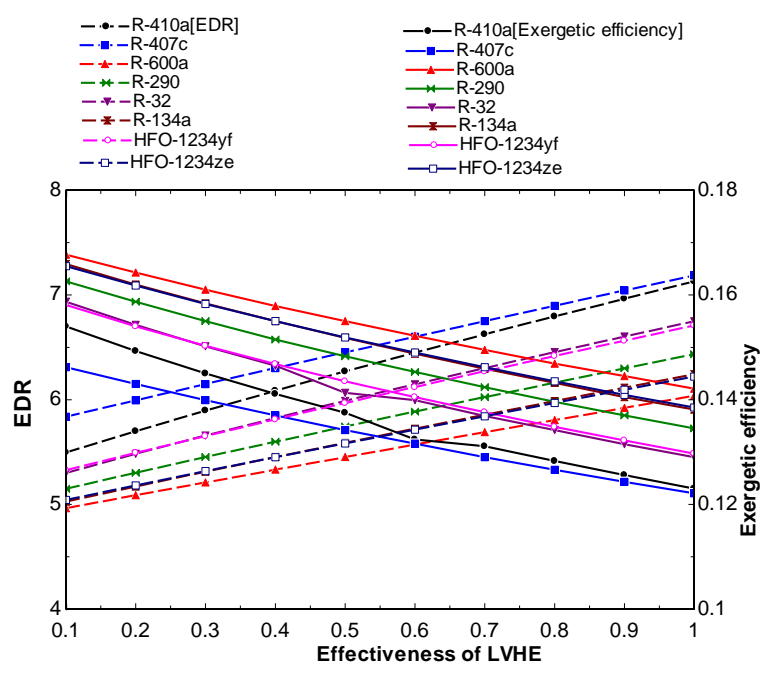

Figure 12: shows the variation of EDR and exergetic efficiency vs Effectiveness of liquid vapour heat exchanger $(\varepsilon$, lvhe $)(\mathrm{Te}=273 \mathrm{~K}, \mathrm{Tc}=318 \mathrm{~K})$

Figure 11-12, shows the effect of effectiveness of lvhe on

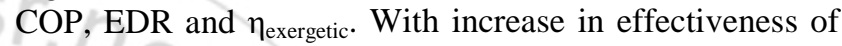
LVHE, COP and $\eta_{\text {exergetic }}$ decreases because with increase in effectiveness of lvhe degree of subcooling increases and also superheating of suction vapour takes place i.e. increase in compressor work whereas EDR increases for all the refrigerants taken for the consideration. The effect of increase in refrigerating effect is counteract by increase in compressor work hence COP of system decreases. COP of the system decreases by $20.09 \%, 16.47 \%, 15.25 \%$, $17.27 \%, 18.70 \%, 16.81 \%, 17.93 \%, 16.28 \%$ for refrigerant R-410a，R-407c，R-600a，R-290，R-32，R-134a，HFO1234yf, HFO-1234ze respectively. It is clearly shown that COP decrease highest in case of R-410a. Similar trends have been shown by $\eta_{\text {exergetic }}$ curves.

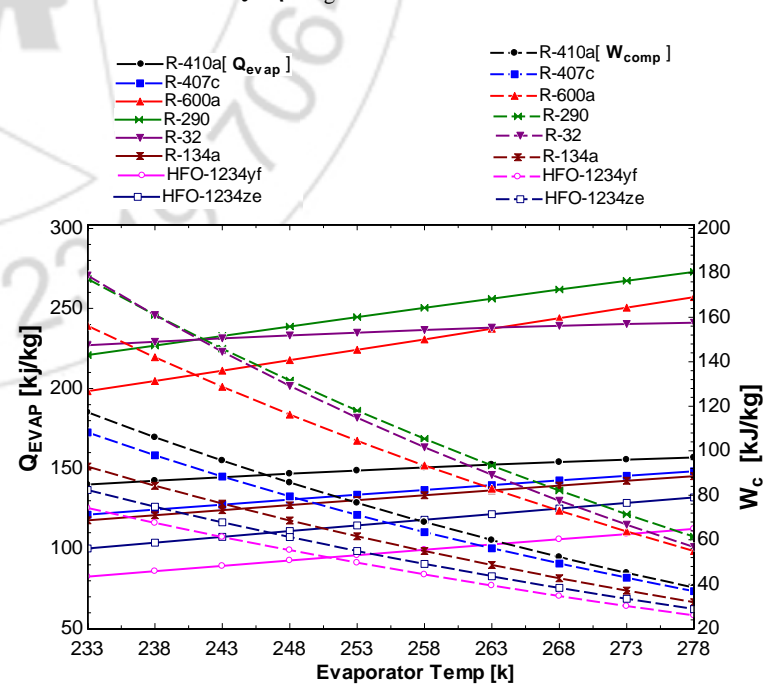

Figure 13: shows the variation of refrigerating effect and compressor work vs evaporator temp [k]

Figure 13, depicts that as the evaporator temperature increases refrigerating effect increases due to subcooling and superheating in the LVHE and hence compressor work decreases, finally COP of the system increases. Compressor work is highest in case of R-290 at higher evaporator temp and for R-32 at lower evaporator temp. Compressor is least in case of HFO-1234yf and HFO$1234 z e$, reverse is true for refrigerating effect. 


\section{International Journal of Science and Research (IJSR) \\ ISSN (Online): 2319-7064 \\ Index Copernicus Value (2013): 6.14 | Impact Factor (2015): 6.391}

\section{Conclusions}

In the exergy analysis of eight eco-friendly refrigerant in a vapour compression cycle incorporated with a liquid vapour heat exchanger, following conclusion can be made which are summarized below.

1. COP and $\eta_{\text {exergetic }}$ of:

a) R-600a is highest closely followed by HFO-1234ze.

b) HFO-1234yf and R-407c are least at lower evaporator temp and at higher evaporator temp respectively.

c) The COP of R-600a, HFO-1234ze, R-134a, R-290, HFO-1234yf, R-32, R-410a is $16.33 \%, 13.87 \%, 13.25 \%$, $10.47 \%, 7.58 \%$, $5.71 \%, 1.39 \%$ is higher than $\mathrm{R}-407 \mathrm{c}$ respectively at evaporator temp of $278 \mathrm{k}$.

2. From the exergy destruction viewpoint or irreversibility, the worst component is condenser, followed by throttle valve, evaporator, compressor and lvhe is the most efficient one. HFO-1234yf is the most efficient refrigerant, since it shows least irreversibility or exergy destruction in the entire component.

3. Refrigerating effect is least in case of HFO-1234yf and highest in case of R-290. Reverse is true for compressor work.

4. COP of R-410a, R-407c, R-600a, R-290, R-32, R-134a, HFO-1234yf, HFO-1234ze decreased by $20.09 \%$, $16.47 \%$, $15.25 \%$, $17.27 \%$, 18.7\%, $16.81 \%$, $17.93 \%$, $16.28 \%$ respectively when effectiveness of lvhe is increased from 0 to 1 .

From above discussion it is clear that HFO-1234yf shows eco-friendly characteristic i.e. least irreversibility in all the

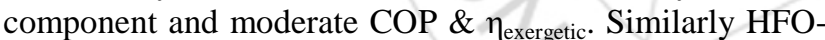
1234ze shows promising result. Although R-600a has highest COP, ultra low GWP, zero ODP, however exergy destruction is found to be more for R-600 and R-290, R32. Although flammability issue is associated with these refrigerants. Hence hydrofluoroolefins are the next generation refrigerants.

\section{References}

[1] P. K. Nag, Engineering Thermodynamics, Available energy, Availability and Irreversibility, Tata McGraw Hill Education private limited, 209-240,2011

[2] S.A. Klein and F. Alvarado, Engineering Equation Solver, F Chart software, Middleton, WI, Version9.224,2012.

[3] T.J. Leck, "New High Performance, LOW GWP Refrigerants for Sationary AC and Refrigeration," 13th International Refrigeration and Air Conditioning Conference at Purdue, West Lafayette,2160,1-8,2010.

[4] C. Zilio, S.S. Brown and A. Cavallini, "Simulation of R-1234yf performance in a typical automotive system.," Proceedings of the 3rd Conference on Thermophysical Properties and Transfer Processes of
Refrigeration, Boulder, CO, USA, Paper No. 128, 2009.

[5] United Nation Environment Programme (UNEPS). The Montreal protocol on substances that deplete the ozone layer 1997.

[6] United Nations 2011 Kyoto protocol to the United Nations Framework Convention on Climate Change. http://untccc.int //resource/docs/convkp/kpeng.pdf.

[7] M. Mohanraj, S. Jayaraj, C. Muraleedharan, 2009.Environment friendly alternatives to halogenated refrigerants -A review. International Journal of Greenhouse Gas control 3, 108-119.

[8] V.P. Venkataramanamurthy, Dr. P. Senthil Kumar, 2010. Experimental Comparative energy, exergy flow and s4econd law efficiency analyses of R22, R436b vapour compression refrigeration cycles. International Journal of science and Technology 2 (5), 1399-1412.

[9] C. Aprea, A. Greco, 2002. An exergetic analysis of R22 substitution. Applied Thermal Engineering 22, 1455-1469.

[10] Jyoti Soni, R.C. Gupta, Exergy Analysis of Vapour Compression Refrigeration System with Using R407C and R-410AInternational Journal of Engineering Research \& Technology (IJERT) Vol. 1 Issue 7, September - 2012 ISSN: 2278-0181.

[11] V.Siva Reddy, N.L.Panwar, S. C.Kaushik Exergetic analysis of avapour compression refrigeration system with R134a, R143a, R152a, R404A, R407C, R410A, R502 and R507ASpringer-Verlag 2011.

[12]Bilal Ahmed Qureshi and Syed M Zubair, "Performance Degradation of a Vapour Compression Refrigeration System Under Fouled Conditions", International Journal of Refrigeration, Vol. 34, (2011), pp. 1016-1027.

[13] "Official Journal of the European Union," Directive 2006/40/EC of the European Parliament and of the Council, 14.6.2006.

[14]E.W. Lemmon, M. L. Huber and M. O. McLinden, "NIST Standard Reference Database23:Reference Fluid Thermodynamic and Transport Properties," REFPROP, Version 9.0. National Institute of Standards and Technology, Standard Reference Data Program. Gaithersburg, 2010

\section{Author Profile}

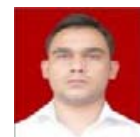

Shobhit Mishra is currently pursuing masteres degree program in Thermal engineering in Department of Mechanical Engineering, Jamia Millia Islamia, Delhi (India)

M. Emran Khan Professor Mechanical Engineering Department, Jamia Millia Islamia, Delhi, (India) 